\title{
Brief Study on Domestication and Foreignization in Translation
}

\author{
Wenfen Yang \\ School of Foreign Languages, Qingdao University of Science and Technology, Qingdao, China \\ Email: wfyoung@163.com
}

\begin{abstract}
This essay gives a brief study of Domestication and Foreignization and the disputes over these two basic translation strategies which provide both linguistic and cultural guidance. Domestication designates the type of translation in which a transparent, fluent style is adopted to minimize the strangeness of the foreign text for target language readers; while foreignization means a target text is produced which deliberately breaks target conventions by retaining something of the foreignness of the original. In the contemporary international translation field, Eugene Nida is regarded as the representative of those who favour domesticating translation, whereas the Italian scholar Lawrence Venuti is regarded to be the spokesman for those who favour foreignizing translation, who has also led the debate to a white-hot state.
\end{abstract}

Index Terms - domestication, foreignization, translation strategies

\section{OVERVIEW OF DOMESTICATION AND FOREIGNIZATION}

Domestication and foreignization are two basic translation strategies which provide both linguistic and cultural guidance. They are termed by American translation theorist L.Venuti (qtd. in Schaffner 1995:4). According to Venuti, the former refers to "an ethnocentric reduction of the foreign text to target-language cultural values, bring the author back home," while the latter is "an ethnodeviant pressure on those (cultural) values to register the linguistic and cultural difference of the foreign text, sending the reader abroad." (Venuti 1995: 20) Generally speaking, domestication designates the type of translation in which a transparent, fluent style is adopted to minimize the strangeness of the foreign text for target language readers, while foreignization means a target text is produced which deliberately breaks target conventions by retaining something of the foreignness of the original (Shuttleworth \& Cowie 1997:59).

Disputes over domestication and foreignization have existed for a long time. However, till 1950s and 1960s, when the more systematic, and mostly linguistic-oriented, approach to the study of translation began to emerge (Jeremy 2001:9), the focus had been on the linguistic level. Since the cultural turn appeared in 1970s, the dispute has been viewed from a brand new perspective - social, cultural and historical. The conflict between domestication and foreignization as opposite translation strategies can be regarded as the cultural and political rather than linguistic extension of the time-worn controversy over free translation and literal translation (Wang Dongfeng 2002: 24).

Seen from this, liberal translation and literal translation are not synonymous to domestication and foreignization, but they may overlap sometimes. Foreignness in language or culture can serve as a standard to judge whether a translation is domesticated or foreignized. Literal and liberal translations are techniques to tackle the linguistic form and they are two ways to transcode language. Domestication and foreignization, however, are concerned with the two cultures, the former meaning replacing the source culture with the target culture and the latter preserving the differences of the source culture. Only when there are differences in both linguistic presentation and cultural connotation, domestication and foreignization exist.

Nida (2001:82) points out that "For truly successful translation, biculturalism is even more important than bilingualism, since words only have meanings in terms of the cultures in which they function." Cultural gaps between the source language and the target language have always turned to be a hard nut for translators to crack. Christiane.Nord (2001:34) holds that "translating means comparing cultures."

A brief retrospect may facilitate deeper understanding about the question under discussion. For the sake of convenience, the authoress here follows two clues, namely, studies abroad and studies at home.

\section{STUDIES ABROAD}

Many of translation theories from Cicero (106-43 B.C.) to the twentieth century centred on the recurring and sterile debate as to whether translation should be literal (word-for-word) or free (sense-for-sense), a dyad that is famously discussed by St Jerome in his translation of the Bible into Latin. Controversy over the translation of the Bible and other religious texts was central to translation theory for over a thousand years (Jeremy 2001:33). However, according to Routledge Encyclopedia of Translation Studies (Baker 1998: 242), the domestication strategy has been implemented at least since ancient Rome, when, as Niethzshe remarked, "translation was a form of conquest" and Latin poets like Horace and Propertius translated Greek text into the Roman present. A foreignizing strategy was first formulated in German culture during the classical and Romantic periods, perhaps most decisively by the philosopher and theologian 
Friedrich Schleiermacher. In his famous lecture On the Different Ways of Translation, Friedrich Schleiermacher demanded that translations from different languages into German should read and sound different: the reader should be able to guess the Spanish behind a translation from Spanish, and the Greek behind a translation from Greek. He argued that if all translations read and sound alike, the identity of the source text would be lost, levelled in the target culture.

In the contemporary international translation field, the person who has initiated the controversy between domestication and foreignization is Eugene Nida, whom is regarded as the representative of those who favour domesticating translation. While it is the Italian scholar Lawrence Venuti who has led the debate to a white-hot state. He can be regarded as the spokesman for those who favour foreignizing translation.

\section{A. Nida's Formal and Functional Equivalences}

Nida differentiates between two types of equivalences: formal and dynamic (or functional) as basic translation orientations. Formal equivalence focuses attention on the message itself, in both form and content. It is a means of providing some insight into the lexical, grammatical or structural form of a source text, which is similar to literal translation. Functional equivalence, however, is based on the principle of equivalent effect, i.e. the relationship between receiver and message should aim at being the same as that between the original receivers and the SL message. In language, Culture and Translating, a minimal definition of functional equivalence is stated as "the readers of a translated text should be able to comprehend it to the point that they can conceive of how the original readers of the text must have understood and appreciated it." The maximal, ideal definition is stated as "the readers of a translated text should be able to understand and appreciate it in essentially the same manner as the original readers did." (Nida 1995: 118)

In fact Nida's functional equivalence is based on and is used to guide the translation of Bible. His translation work, splendid though it is, comes out of a specific purpose: the translation of a Christian text with the goal of converting non-Christians to a different spiritual viewpoint. In order to entail a good understanding and operative function for the receptors of the target language, the message in the Bible with the meaning in Latin "do not let your left hand know what your right hand is doing" can be rendered in English as "do it in such a way that even your closest friend will not know about it". Nida points out that this translation first avoids the possible misunderstanding by the receptors and thus makes clear the tangible reference to present-day circumstances of life. This practice may be acceptable in translating Bible, but in handling cultural factors in texts other than Biblical one, functional equivalence is inadequate and even misleading. Peter Newmark thinks that Nida's functional equivalence has done too much for the readers by rendering everything so plain, so easy. He states "Following Nida's 'Translating is communicating' with its emphasis on a readable, understandable text (although Nida also insists on accuracy and fidelity), one notices inevitably a great loss of meaning in the dropping of so many Biblical metaphors which, Nida insists, the reader cannot understand.”(Newmark 2001a: 51)

\section{B. Venuti's Foreignization vs. Domestication: Resistance against the Anglo-American Culture}

Venuti's foreignizing strategy is put forward in the "aggressive monolingual" cultural background such as the Anglo-American culture. As a staunch advocate of foreignization, Venuti believes there is violence residing in the very purpose and activity of domestication. He holds that the phenomenon of domestication involves 'an ethnocentric reduction of the foreign text to [Anglo-American] target-language cultural values'. This entails translating in a transparent, fluent, 'invisible' style in order to minimize the foreignness of the TT (Jeremy 2001:146). Venuti proposes the strategy of "resistant translation"( i.e. foreignization) against the tradition of "smooth translation". He argues that foreignization "entails choosing a foreign text and developing a translation method along lines which are excluded by dominant cultural values in the target language (Venuti 1997: 242).

Foreignization produces "something that cannot be confused with either the source-language text or a text written originally in the target language." (qtd. in Albrecht 1992:4) Venuti (1995: 20) considers the foreinizing method to be 'an ethnodeviant pressure on [target-language culture] values to register the linguistic and cultural difference of the foreign text, sending the reader abroad'. It is 'highly desirable', he says, in an effort 'to restrain the ethnocentric violence of translation'. In other words, the foreignizing method can restrain the 'violently' domesticating cultural values of the English-language world (qtd. in Jeremy 2001:147). In summary, foreignization advocated by Venuti and his followers is a non-fluent or estranging translation style designed to make visible the presence of the translator by highlighting the foreign identity of the ST and protecting it from the ideological dominance of the target culture(ibid: 147). According to Venuti, domestication and foreignization are 'heuristic concepts' rather than binary opposites. They may change meaning across time and location. What dose not change, however, is that domestication and foreignization are 'deal with the question of how much it rather signals the differences of that text' (ibid: 148).

\section{Other Studies}

In the 1970s, polysystem theory was developed by the Israeli scholar Itamar Even-Zohar. A literary work is studied as part of a literary system, which itself is defined as 'a system of functions of the literary order which are in continual interrelationship with other orders' (Tynjanov 1927: 71-72, Jeremy 2001: 109). Literature is thus part of the social, cultural, literary and historical framework and the key concept is that of the system(Jeremy 2001: 109). According to polysystem hypothesis, the translators in a strong literary polysystem tend to apply domesticating strategy and thus 
produce translations characterized by superficial fluency, while in a weak culture foreinizing strategy or resistant translation prevails (Zohar 1978: 7-8).

Almost contemporary with Zohar's polysystem theory, the cultural studies proposed by Andre Lefevere and Susan Bassnett also provide a new perspective on the problem of domestication and foreignization. Generally speaking, Lefevere and Bassnett agree with Nida's 'complete naturalness of expression'. The difference is that Nida's 'equivalence' is at the level of linguistics while Lefevere and Bassnett seek for a cultural equivalence. Both of them attach great attention to the type of target readers, considering the nature of the text as well. Bassnett also proposes that different historical periods require different translation norms. The specific translation strategy adopted, domestication or foreignization, could reflect and in turn, determine the social and cultural trend in the contemporary society.

Also in the 1970s, skopos, the Greek word for 'aim' or 'purpose', was introduced into translation theory and developed by Hans J. Vermeer. His idea is then extended by some second-generation skopos theorists, most notably, Christiane Nord. In the framework of skopos theory, "translate means 'to produce a text in a target setting for a target purpose and target addresses in target circumstances." (Nord 2001:12) According to skopos theory, the top-ranking rule for any translational action is the 'skopos rule'. This rule is intended to solve the eternal dilemmas of free vs. faithful translation, domestication vs. foreignization, etc. It means that the Skopos of a particular translation task may require a 'domestication' or a 'foreignization', or anything between these two extremes, depending on the purpose for which translation is needed. What it does not mean is that a good translation should ipso facto conform or adapt to target-culture behaviour or expectations, although the concept is often misunderstood in this way (Nord 2001: 29).

\section{STUDIES AT HoME}

In China, from the 1980s, there are also many debates over domestication and foreignization. In 1987, Liu Yingkai published his paper Domestication - The Wrong Track of Translation in which he pointed out the prevalence of domestication in Chinese translation field. Liu summed up the manifestation of domestication in five forms: (1) the abuse of four-word idioms; (2) the abuse of words of classic elegance; (3) the abuse of abstraction; (4) the abuse of replacement; (5) the abuse of allusions and images. Liu (Liu in Yang, 1994: 269) argues that domesticating translation, by assimilating the national characteristics of the ST, distorts the ST and may efface the national features of a culture. $\mathrm{Xu}$ Yuanchong favors domesticating translation. He (Xu 2000:2) sees clearly the differences between eastern and western cultures, and proposes the theory of cultural competition to deal with the cultural differences. That is, a translator should make full use of the strength of the TL in order to make the TT more beautiful. For example, as using of four-character-phrases is widely acknowledged as one of the characteristics as well as strong points of the Chinese language, $\mathrm{Xu}$ uses a lot of four-character phrases in his translation. He also likes to use phrases from ancient Chinese literary works in his translation.

In 2002, Chinese Translation Journal alone published six papers on translation strategies from the perspective of cross-cultural communication. As a whole the voice for foreignization dominates. Sun Zhili, a representative of foreignization, thinks that the primary task of translating is to precisely and fully convey the thought and style of the source text. He predicts foreignization will be the preferred strategy of literary translation in China in the $21^{\text {st }}$ century (Sun Zhili 2002: 40-44). Sun's opinion confronts some disagreements. Cai Ping, for instance, says that domestication should be the main stream in literary translation. Cai further explains the essential purpose of translation is to communicate, to lead readers to a good understanding of the source text. A heavily foreignized translation may be too foreign for readers to identify with, let alone to appreciate. In retrospect of translation history, Cai concludes that with the passage of time, foreignization always gives way to domestication (Cai Ping 2002: 39-41). Xu Jianping holds a compromise proposal. He distinguishes two types of source texts: in English and in Chinese. Xu suggests that in order to fulfil cross-cultural communication, foreignization should be used in English-Chinese translation with domestication as supplement, while in Chinese-English translation, domestication should be used as much as possible. The reason is that an enormous group of Chinese readers eager to accept the foreign elements known of the foreign culture far more than foreign readers do about the Chinese culture (Xu Jianping 2002: 36-38).

The wild variety of viewpoints presented to be for or against domestication or foreignization are from different perspectives. In fact, both domestication and foreignization have their advantages and disadvantages. Domesticating translation is easier for the readers to understand and accept. However, the naturalness and smoothness of the TT are often achieved at the expense of the cultural and stylistic messages of the ST. Foreignizing translation preserves the ST formal features and in turn informs the readers of the SL-culture, but alien cultural images and linguistic features may cause the information overload to the reader. In a word, both domestication and foreignization entail losses, as losses are inevitable in the translation process. It's hard to say which strategy is better, if the condition under which a translation is done is not taken into account.

\section{REFERENCES}

[1] Venuti, Lawrence. 1995. The Translator's Invisibility: A History of Translation. London \& New York: Routledge.

[2] Shuttleworth, M. \& M. Cowie. 1997. Dictionary of Translation Studies. Manchester, UK: St Jerome Publishing.

[3] Jeremy Munday.2001. Introducing Translation Studies: Theories and applications. London and New York: Routledge. 
[4] Nida, Eugene. 2001. Language and Culture-Contexts in Translation. Shanghai: Shanghai Foreign Language Education Press.

[5] Nord, Christiane. 2001. Translating as a Purposeful Activity - Functional Approaches Explained. Shanghai: Shanghai Foreign Language Education Press.

[6] Baker, Mona. 1998. Routledge Encyclopedia of Translation Studies. London and New York: Routledge. pp.240-242

[7] Newmark, Peter.2001. Approaches to Translation. Shanghai: Shanghai Foreign Language Education Press.

[8] Even-Zohar, Itmar. 1978. Papers in Historical Poetics, in Benjamin Hrushovski and Itamar Even-Zohar (eds) Papers on Poetics and Semiotics 8. Tel Aviv: University Publishing Projects.

[9] Sun Zhili, 2002. Literature Translation in China: from Domestication to Foreignization , in China Translation, Vol. 1, pp. 40-44.

[10] Xu Jianping, Zhang Rongxi, 2002. Domestication and Foreignization in Cross-Cultural Translation , in China Translation, Vol. 5, pp. 36-38.

[11] Wang Dongfeng, 2002. Domestication and Foreignization: a Contradiction? in China Translation, Vol. 9, pp. 24-26.

[12] Cai Ping, 2002. Foreignization as the Main Method in Translation, in China Translation, Vol. 5, pp. 39-41.

[13] Xu Yuanchong, 2000. New Translation Theory in the New Century, in China Translation, Vol. 4, pp. 2-6.

[14] Liu Yingkai, 1987. Domestication — the Forked Road in Translation, in Yang Zijian and Liu Xueyun (eds) New Viewpoints onTranslation, Hubei: Hubei Education Press, 1994, pp. 269-282. 